\title{
Clinicopathological significance of EZH2 mRNA expression in patients with hepatocellular carcinoma
}

\author{
T Sudo',2, T Utsunomiya', K Mimori', H Nagahara', K Ogawa', H Inoue', S Wakiyama ${ }^{3}$, H Fujita ${ }^{2}$, K Shirouzu² \\ and $M$ Mori*,I \\ 'Department of Surgery, Medical Institute of Bioregulation, Kyushu University, 4546, Tsurumihara, Beppu 874-0838, Japan; ${ }^{2}$ Department of Surgery, \\ Kurume University School of Medicine, 67 Asahi-machi, Kurume 830-00 II, Japan; ${ }^{3}$ Department of Surgery, lizuka Hospital, 3-83 Yoshio-machi, lizuka \\ 820-8505, Japan
}

Enhancer of zeste homologue 2 (EZH2), a member of the polycomb group protein family, plays a crucial role in the regulation of embryonic development and has been associated with the regulation of the cell cycle. Recently, several studies have shown that $\mathrm{EZH} 2$ is highly expressed in aggressive tumours, including human breast cancer, prostate cancer, and lymphomas. We thus analysed EZH2 expression using real-time reverse transcription-polymerase chain reaction, and correlated its expression status with various clinicopathological parameters in 66 patients with hepatocellular carcinoma (HCC). We found high expression of EZH2 in human liver cancer cell lines. Furthermore, EZH2 gene-expression levels in tumour tissue specimens $(0.34 \pm 0.52)$ were significantly higher $(P<0.000 \mathrm{I})$ than those in the corresponding nontumour tissue specimens $(0.07 \pm 0.09)$. The incidence of cancer cell invasion into the portal vein was significantly higher $(P<0.001)$ in the high EZH2 expression group (26 of the 33, 79\%) than in the low expression group ( 13 of the 33, 39\%). However, there was no significant difference in the disease-free survival rate between the two groups. The findings of this study indicate that EZH2 mRNA expression was upregulated in human HCC and may play an important role in tumour progression, especially by facilitating portal vein invasion.

British Journal of Cancer (2005) 92, 1754- 1758. doi:I0.1038/sj.bjc.660253 I www.bjcancer.com

Published online 26 April 2005

(c) 2005 Cancer Research UK

Keywords: EZH2; polycomb group protein; hepatocellular carcinoma; vascular invasion

Polycomb group $(\mathrm{PcG})$ proteins are known to maintain the silenced state of several developmentally regulated genes and to control the transcriptional memory of a cell (Laible et al, 1997; van der Vlag et al, 1999). Dysregulation of this gene-silencing machinery may lead to cancer (Jacobs et al, 1999; Satijin and Otte, 1999). Recently, enhancer of zeste homologue 2 (EZH2), a member of the PcG protein family, has been linked to the aggressiveness of human cancers, including lymphomas (Raaphorst et al, 2000; van Kemenade et al, 2001; Visser et al, 2001; Dukers et al, 2004), breast cancer (Kleer et al, 2003; Raaphorst et al, 2003) and prostate cancer (Sellers and Loda, 2002; Varambally et al, 2002; Rhodes et al, 2003; Foster et al, 2004). Kleer et al (2003) provided biological evidence that overexpression of EZH2 promotes oncogenic transformation. In breast epithelial cells, they observed that high expression of EZH2 induced anchorage-independent growth and cell invasion, behaviours that are hallmarks of cancer. Moreover, they found that higher expression levels of EZH2 protein were strongly associated with decreased disease-free survival and decreased overall survival for patients with breast cancer. In addition, Varambally et al (2002) reported that EZH2 was overexpressed in metastatic prostate cancer and that inhibition of EZH2 blocked prostate cell growth. EZH2 expression has also been demonstrated to have prognostic

*Correspondence: Dr M Mori; E-mail: mmori@beppu.kyushu-u.ac.jp Received 5 October 2004; revised 17 February 2005; accepted 28 February 2005; published online 26 April 2005 significance in patients with prostate cancer (Sellers and Loda, 2002; Varambally et al, 2002; Rhodes et al, 2003; Foster et al, 2004). Therefore, the role of EZH2 in tumour development and progression has recently become a subject of increased interest (Tonini et al, 2004). To the best of our knowledge, however, the clinicopathological and prognostic significance of the EZH2 geneexpression status has not previously been examined in digestive organ cancers. The present study thus focused on examining the relationship between EZH 2 mRNA expression and clinicopathological features of human hepatocellular carcinoma (HCC), using real-time quantitative reverse transcription-polymerase chain reaction ( $\mathrm{RT}-\mathrm{PCR})$.

\section{MATERIALS AND METHODS}

\section{Cell lines}

The human liver cancer cell lines, Hep3B, HepG2 and HuH7, were provided by the Cell Resource Center for Biomedical Research, Institute of Development, Aging and Cancer, Tohoku University, Japan. All cell lines were maintained in an RPMI 1640 medium supplemented with $10 \%$ foetal calf serum and antibiotics. Cultured cells from each cell line were dissolved in $350 \mu$ l of buffer RLT containing $1 \%$ beta-mercaptoethanol and total RNA was extracted and purified by RNeasy Mini Kit (Qiagen, Hilden, Germany) in accordance with the manufacturer's protocols. 


\section{Clinical tissue samples}

In all, 66 patients with HCC who underwent surgery at our institutes were entered in this study. The resected tumour and paired nontumour tissue specimens were immediately frozen in liquid nitrogen and kept at $-80^{\circ} \mathrm{C}$ until analysis. Frozen tissue specimens were homogenised in guanidinium thiocyanate, and total RNAs were obtained by ultracentrifugation through a cesium chloride cushion as described previously (Mori et al, 1995; Utsunomiya et al, 2002a). Written informed consent was obtained from all patients. All patients were closely followed after surgery at regular 1-month intervals.

\section{Real-time quantitative RT - PCR}

Sense and antisense primers encoding the middle portion of the EZH2 gene located on chromosome 7q35, including intron and exon sequences, were designed and constructed. The sequences of the EZH2 primers were as follows: sense primer, $5^{\prime}$-TTGTTGGCGG AAGCGTGTAAAATC- $3^{\prime}$; and antisense primer, $5^{\prime}$-TCCCTAGTCC CGCGCAATGAGC-3'. Glyceraldehyde-3-phosphate dehydrogenase $(G A P D H)$ was used as an internal control. The sequences of the GAPDH primers were as follows: sense, $5^{\prime}$-TGAACGGGAAGCTCA CTGG-3'; and antisense, $5^{\prime}$-TCCACCACCCTGTTGCTGTA- $3^{\prime}$. Realtime monitoring of the PCR reactions was performed using the LightCyclerTM system (Roche Applied Science, Indianapolis, IN, USA) and SYBR green I dye (Roche Diagnostics). Monitoring was performed according to the manufacturer's instructions, as described previously (Utsunomiya et al, 2002b; Ogawa et al, 2004). In brief, a master mixture was prepared on ice containing $1 \mu \mathrm{l}$ of cDNA of each gene, $2 \mu \mathrm{l}$ of LC DNA Master SYBR Green I mix, $50 \mathrm{ng}$ of primers and $2.4 \mu \mathrm{l}$ of $25 \mathrm{mM} \mathrm{MgCl}_{2}$. The final volume was then adjusted to $20 \mu \mathrm{l}$ with water. After the reaction mixture was loaded into the glass capillary tube, PCR was carried out under the following cycling conditions: initial denaturation at $95^{\circ} \mathrm{C}$ for $10 \mathrm{~min}$, followed by 35 cycles of denaturation at $95^{\circ} \mathrm{C}$ for $1 \mathrm{~min}$, annealing at $56^{\circ} \mathrm{C}$ for $1 \mathrm{~min}$ and extension at $72^{\circ} \mathrm{C}$ for $1 \mathrm{~min}$. After amplification, the products were subjected to a temperature gradient from 68 to $95^{\circ} \mathrm{C}$ at $0.2^{\circ} \mathrm{C} \mathrm{s}^{-1}$ under continuous fluorescence monitoring to produce a melting curve of the products. We determined the expression levels of EZH2 and GAPDH by comparison with Hep3B cDNA. The fit point method was employed to determine the cycle in which the log-linear signal was first distinguishable from the baseline, and that cycle number was then used as a crossing-point value. The standard curve was produced by measuring the crossing point of each standard value and plotting them against the logarithmic value of concentration. The EZH2 concentration of each sample was calculated by plotting their crossing points against the standard curve. $E Z H 2$ concentration was then divided by the concentration of endogenous reference $(G A P D H)$ to obtain normalised EZH2 expression. Each assay was performed three times to verify the results, and the mean mRNA expression was used for the statistical analysis.

\section{Immunohistochemical analysis}

Several formalin-fixed and paraffin-embedded tissue sections corresponding to the samples used for mRNA expression analysis were analysed. Tissue sections were deparaffinised, soaked in $0.01 \mathrm{M}$ sodium cytorate buffer and boiled in an electronic oven for $15 \mathrm{~min}$ at $500 \mathrm{~W}$ to retrieve cell antigens. The tissue sections were immunohistochemically stained using the streptavidin-biotin peroxidase method (Universal Dako Cytomation LSAB ${ }^{\circledR}$ kit; Dako, Kyoto, Japan) with a primary antibody against EZH2 (rabbit polyclonal antibody; ABGENT, San Diego, USA). In brief, the sections were blocked by $3 \% \mathrm{H}_{2} \mathrm{O}_{2}$ for $5 \mathrm{~min}$ and incubated overnight with primary antibody at $4{ }^{\circ} \mathrm{C}$. The samples were then washed with TBS buffer and subsequently incubated with secondary antibody for $30 \mathrm{~min}$.

\section{Statistical analysis}

The data obtained from real-time RT-PCR and the patients' clinicopathological variables were processed by the statistical software JMP (SAS Institute Inc., Cary, NC, USA). The Student's $t$-test and the $\chi^{2}$ test with Yates' correction factor were used. The postoperative disease-free survival rate was calculated by the Kaplan-Meier method, and the differences in survival between the groups were compared using the log-rank test. The findings were considered to be significant when their $P$-value was less than 0.05 .

\section{RESULTS}

\section{Expression of EZH2 in cell lines and clinical samples}

We first examined EZH2 mRNA expression in three human liver cancer cell lines and found sufficient EZH2 expression in all the cell lines (Figure 1). We then determined the levels of EZH2 mRNA expression by comparisons with Hep3B as the

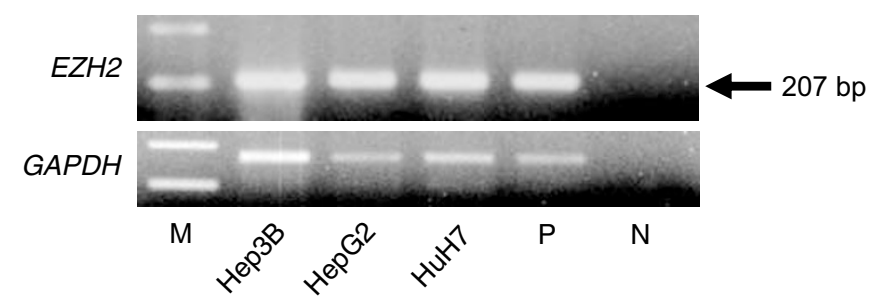

Figure I Expression of $E Z H 2$ in three liver cancer cell lines (Hep3B, HepG2 and HuH7). M: marker; P: positive control (Human Universal Reference total RNA, Clontech, Palo Alto, CA, USA); N: negative control (distilled water); GAPDH: glyceraldehyde-3-phosphate dehydrogenase.

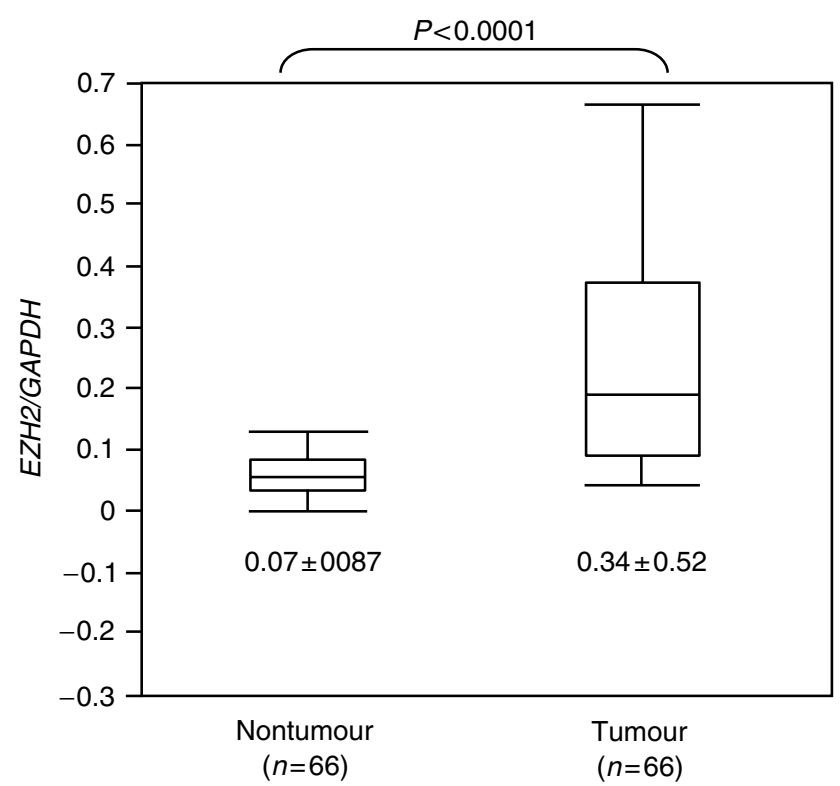

Figure 2 Expression levels of $E Z H 2$ quantitatively determined by realtime RT-PCR for 66 pairs of tumour and nontumour tissue specimens. The correction values of $E Z H 2$ expression were calculated by dividing the EZH2 amounts by the amount of endogenous reference (GAPDH) concurrently examined on the same samples. 
quantifying standard, which express human EZH2 sufficiently. The mean expression level of EZH2 mRNA in tumour tissue specimens, $0.34 \pm 0.52$, was significantly higher than the mean expression level, $0.07 \pm 0.09$, of $E Z H 2$ in the corresponding nontumour tissue specimens $(P<0.0001)$, as shown in Figure 2. Patients with mRNA expression levels in tumour tissue less than the median value of 0.14 formed the low expression group $(n=33)$, while patients with mRNA expression levels in tumour tissue equal to or greater than 0.14 formed the high expression group $(n=33)$.
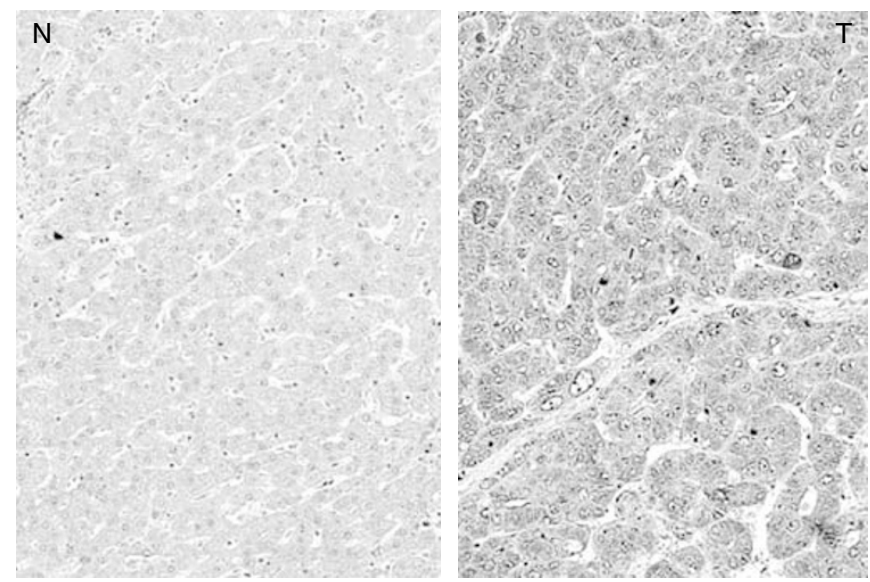

Figure 3 An immunohistochemical analysis for $E Z H 2$ in $\mathrm{HCC}$. EZH2 immunostaining was strongly positive in the cytoplasm of the HCC cells, whereas it was weakly positive in the corresponding normal liver cells. $\mathrm{N}$ : nontumour tissue; $\mathrm{T}$ : tumour tissue.

\section{Immunohistochemical staining}

To visualise the localisation of EZH2 protein, immunohistochemical studies were performed in the resected HCC tissue specimens. Representative findings are shown in Figure 3. EZH2 staining was markedly stronger in the cytoplasm of HCC cells than in the cytoplasm of noncancerous hepatocytes. These findings corresponded well with the results of real-time RT-PCR analysis.

\section{EZH2 mRNA expression and clinicopathological characteristics}

Clinicopathological factors analysed according to the General Rules for Clinical and Pathological Study of Primary Liver Cancer (Liver cancer study group of Japan, 2000) are shown in Table 1 in relation to EZH2 mRNA expression in tumour tissue. No significant differences in host factors, such as the patient's age, sex and the results of liver function tests, were observed between the high and low expression groups. On the other hand, the incidence of cancer cell invasion to the portal vein was significantly higher $(P<0.001)$ in the high expression group $(26$ of the $33,79 \%$ ) than in the low expression group (13 of the 33, $39 \%)$. Other pathological variables, such as the tumour diameter, capsular formation and intrahepatic metastasis, did not significantly correlate with the EZH2 expression status in tumour tissue specimens. Comparison of the disease-free survival rates of the low expression $(n=33)$ and high expression $(n=33)$ groups, shown in Figure 4, revealed no significant difference in the disease-free survival rate between the two groups.

\section{DISCUSSION}

Recent studies have shown that EZH2 is highly expressed in several advanced cancers (Raaphorst et al, 2000; van Kemenade et al, 2001;

Table I Clinicopathological data and EZH2 mRNA expression in the tumour tissue specimens from 66 patients with HCC

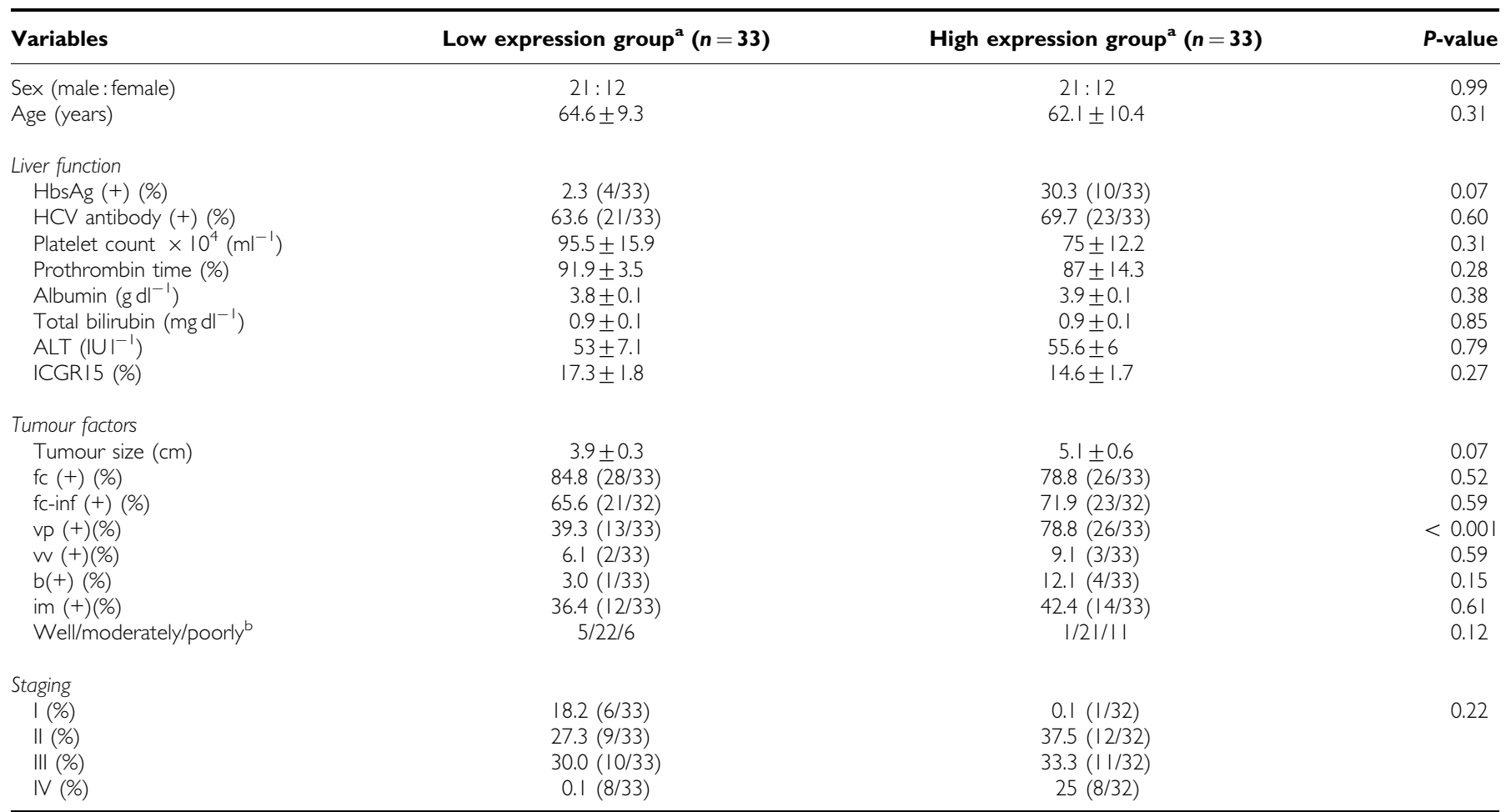

$\mathrm{HCC}=$ hepatocellular carcinoma; $\mathrm{HBs} A g=$ hepatitis $B$ surface antigen; $\mathrm{HCV}=$ hepatitis $\mathrm{C}$ virus; $\mathrm{AST}=$ aspartate transaminase; ICG RI5 = indocyanine green dye retention test at $15 \mathrm{~min} ; \mathrm{fc}=$ capsular formation; $\mathrm{fc}$-inf = tumour invasion to fc; $\mathrm{vp}=$ invasion to portal vein; $\mathrm{w}=$ invasion to hepatic vein; $\mathrm{b}=$ invasion to bile duct; im = intrahepatic metastasis. ${ }^{a}$ The low and high expression groups were determined by a median value of EZH2 mRNA in the 66 tumour tissue specimens. ${ }^{b}$ Histologic differentiation of the tumour. 


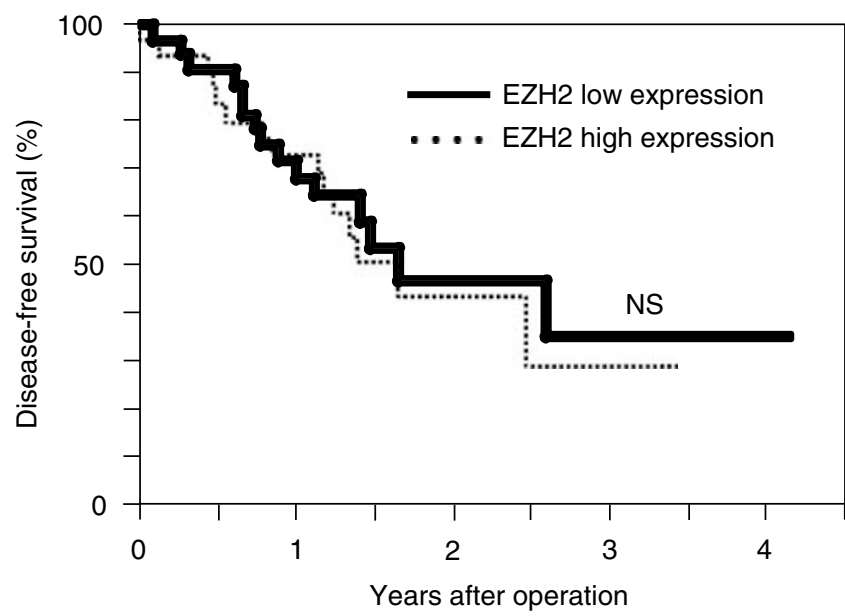

Figure 4 Kaplan-Meier disease-free survival curves for the high expression group $(n=33)$ and the low expression group $(n=33)$. The difference in disease-free survival rate between the two groups was not significant.

Visser et al, 2001; Sellers and Loda, 2002; Varambally et al, 2002; Kleer et al, 2003; Rhodes et al, 2003; Raaphorst et al, 2003; Dukers et al, 2004; Foster et al, 2004). The question naturally arises whether $E Z H 2$ actually contributes to tumour development or whether it is just a biomarker of tumour progression. Bracken et al (2003) provided evidence for $E Z H 2$ being an actual contributor to tumour development by demonstrating that $E Z H 2$ is located downstream in the retinoblastoma protein (pRB) pathway and is an essential downstream mediator of E2F function, which is required for cell proliferation. Bracken et al also demonstrated a direct link between the pRB-E2F growth control pathway and chromatin modifications and identified $E Z H 2$ as a strong candidate oncogene. Tonini et al showed that $E Z H 2$ reverses $\mathrm{pRb} 2 / \mathrm{p} 130$-histone deacetylase-mediated repression of the cyclin A promoter, suggesting a molecular mechanism linking increased EZH2 expression with malignant transformation (Tonini et al, 2004).

Although an association between the tumour aggressiveness and the overexpression of EZH2 has been well documented for breast cancer (Kleer et al, 2003; Raaphorst et al, 2003) and prostate cancer (Sellers and Loda, 2002; Varambally et al, 2002; Rhodes et al, 2003; Foster et al, 2004), little is known about the expression status of $E Z H 2$ in digestive organ cancers. In the present study, we found that $E Z H 2$ mRNA was highly expressed in human liver cancer cell lines as well as in primary tumours from HCC patients.

We then examined the clinicopathological features of EZH2 expression in HCC patients. Interestingly, we observed a statistically significant difference in the incidence of portal vein invasion between the high expression group (79\%) and the low expression group (39\%). Molecular mechanisms linking high $E Z H 2$ expression with an increased incidence of HCC portal vein invasion are not known at present. However, Varambally et al (2002) provided evidence that metastatic PC3 prostate cancer cells treated with EZH2 small interference RNA showed a marked inhibition of cell growth and proliferation. Kleer et al reported that cells forming intravascular tumour emboli had markedly increased $E Z H 2$ expression, suggesting that EZH2 may play an important role in vascular invasion and breast cancer metastasis. Furthermore, Kleer et al (2003) confirmed the invasive properties of EZH2-overexpressing cells both in an in vitro assay, using a basement membrane invasion chamber, as well as in an in vivo assay, using a chicken chorioallantoic membrane.

Since the presence of portal vein invasion is one of the most important prognostic factors for HCC patients (Izumi et al, 1994; Shimada et al, 1998; Ikai et al, 2004), we therefore investigated a possible correlation between $E Z H 2$ mRNA values, quantitatively determined by a real-time RT-PCR, and the prognosis of HCC patients. In the present study, however, we found no significant difference in the disease-free survival rate between the high expression group and the low expression group. This finding appears to be inconsistent with previous studies reporting on the prognostic implications of increased $E Z H 2$ expression in patients with breast cancer (Kleer et al, 2003; Raaphorst et al, 2003) and prostate cancer (Sellers and Loda, 2002; Varambally et al, 2002; Rhodes et al, 2003; Foster et al, 2004). Differences in tumour aggressiveness between HCC and breast or prostate cancer may explain such discrepant results, because the prognosis of patients with HCC (30\% 4-year disease-free survival rate in this study) is markedly worse in general than the prognosis of patients with breast or prostate cancer. Alternatively, these results may suggest that EZH2 expression status is strongly associated with prognosis only in patients with malignancies from hormonally regulated tissues such as breast and prostate (Kleer et al, 2003).

In conclusion, the present study demonstrated that the expression of EZH2 mRNA was upregulated in primary HCC tissues and was associated with a significantly increased incidence of portal vein invasion. Therefore, the EZH2 expression status may be a significant indicator for identifying the malignant potential of human HCC. However, the precise function of EZH2 in digestive organ cancers such as HCC remains unclear. Further investigation is therefore needed to clarify the relationship between EZH2 and disease progression in cancer patients.

\section{ACKNOWLEDGEMENTS}

We thank Ms M Kasagi and Ms M Oda for excellent assistance with RT-PCR and Ms T Shimooka for extraordinary assistance with the cell cultures. This work was supported in part by the following grants and foundations: Grants-in-Aid for Scientific Research (B) (Nos. 15390398, 15390379 and 16390381) and (C) (Nos. 15591412 and 15591411) and a Grant-in-Aid for Exploratory Research (No. 16659337) from the Japan Society for Promotion of Science; and a Health and Labor Sciences Research Grant on Hepatitis and BSE (No. 14230801) from the Ministry of Health, Labor and Welfare of Japan.

\section{REFERENCES}

Bracken AP, Pasini D, Capra M, Prosperini E, Colli E, Helin K (2003) EZH2 is downstream of the pRB-E2F pathway, essential for proliferation and amplified in cancer. EMBO J 22: 5323-5335

Dukers DF, van Galen JC, Giroth C, Jansen P, Sewalt RG, Otte AP, KluinNelemans HC, Meijer CJ, Raaphorst FM (2004) Unique polycomb gene expression pattern in Hodgkin's lymphoma and Hodgkin's lymphomaderived cell lines. Am J Pathol 164: 873-881

Foster CS, Falconer A, Dodson AR, Norman AR, Dennis N, Fletcher A, Southgate C, Dowe A, Dearnaley D, Jhavar S, Eeles R, Feber A, Cooper CS
(2004) Transcription factor E2F3 overexpressed in prostate cancer independently predicts clinical outcome. Oncogene 23: 5871-5879

Ikai I, Arii S, Kojiro M, Ichida T, Makuuchi M, Matsuyama Y, Nakanuma Y, Okita K, Omata M, Takayasu K, Yamaoka Y (2004) Reevaluation of prognostic factors for survival after liver resection in patients with hepatocellular carcinoma in a Japanese nationwide survey. Cancer 101: 796-802

Izumi R, Shimizu K, Ii T, Yagi M, Matsui O, Nonomura A, Miyazaki I (1994) Prognostic factors of hepatocellular carcinoma in patients undergoing hepatic resection. Gastroenterology 106: 720-727 
Jacobs JJ, Kieboom K, Marino S, DePinho RA, van Lohuizen M (1999) The oncogene and polycomb-group gene bmi-1 regulates cell proliferation and senescence through the ink4a locus. Nature 397: 164-168

Kleer CG, Cao Q, Varambally S, Shen R, Ota I, Tomlins SA, Ghosh D, Sewalt RG, Otte AP, Hayes DF, Sabel MS, Livant D, Weiss SJ, Rubin MA, Chinnaiyan AM (2003) EZH2 is a marker of aggressive breast cancer and promotes neoplastic transformation of breast epithelial cells. Proc Natl Acad Sci USA 100: $11606-11611$

Laible G, Wolf A, Dorn R, Reuter G, Nislow C, Lebersorger A, Popkin D, Pillus L, Jenuwein T (1997) Mammalian homologues of the polycombgroup gene enhancer of zeste mediate gene silencing in Drosophila heterochromatin and at S. cerevisiae telomeres. EMBO J 16: 3219-3232

Liver Cancer Study of Group of Japan (2000) The General Rules for the Clinical and Pathological Study of Primary Liver Cancer 4th edn. pp $11-$ 36. Tokyo: Kanahara Shuppan

Mori M, Mimori K, Inoue H, Barnard GF, Tsuji K, Nanbara S, Ueo H, Akiyoshi T (1995) Detection of cancer micrometastases in lymph nodes by reverse transcriptase-polymerase chain reaction. Cancer Res 55: $3417-3420$

Ogawa K, Utsunomiya T, Mimori K, Tanaka Y, Tanaka F, Inoue H, Murayama S, Mori M (2004) Clinical significance of elongation factor-1 delta mRNA expression in oesophageal carcinoma. $\mathrm{Br} J$ Cancer 91: $282-286$

Raaphorst FM, Meijer CJ, Fieret E, Blokzijl T, Mommers E, Buerger H, Packeisen J, Sewalt RA, Otte AP, van Diest PJ (2003) Poorly differentiated breast carcinoma is associated with increased expression of the human polycomb group EZH2 gene. Neoplasia 5: $481-488$

Raaphorst FM, van Kemenade FJ, Blokzijl T, Fieret E, Hamer KM, Satijn DP, Otte AP, Meijer CJ (2000) Coexpression of BMI-1 and EZH2 polycomb group genes in Reed - Sternberg cells of Hodgkin's disease. Am J Pathol 157: 709-715

Rhodes DR, Sanda MG, Otte AP, Chinnaiyan AM, Rubin MA (2003) Multiplex biomarker approach for determining risk of prostate-specific antigen-defined recurrence of prostate cancer. J Natl Cancer Inst 95: $661-668$
Satijin DP, Otte AP (1999) Polycomb group protein complexes: do different complexes regulate distinct target genes? Biochim Biophys Acta 1447: 1 - 16

Sellers WR, Loda M (2002) The EZH2 polycomb transcriptional repressor a marker or mover of metastatic prostate cancer? Cancer Cell 2: 349-350

Shimada M, Takenaka K, Taguchi K, Fujiwara Y, Gion T, Kajiyama K, Maeda T, Shirabe K, Yanaga K, Sugimachi K (1998) Prognostic factors after repeat hepatectomy for recurrent hepatocellular carcinoma. Ann Surg 227: $80-85$

Tonini T, Bagella L, D’Andrilli G, Claudio PP, Giordano A (2004) Ezh2 reduces the ability of $\mathrm{HDAC} 1$-dependent $\mathrm{pRb} 2 / \mathrm{p} 130$ transcriptional repression of cyclin A. Oncogene 23: 4930-4937

Utsunomiya T, Hara Y, Kataoka A, Morita M, Arakawa H, Mori M, Nishimura S (2002a) Cystatin-like metastasis-associated protein mRNA expression in human colorectal cancer is associated with both liver metastasis and patient survival. Clin Cancer Res 8: $2591-2594$

Utsunomiya $\mathrm{T}$, Inoue $\mathrm{H}$, Taguchi $\mathrm{K}$, Shimada $\mathrm{M}$, Sugimachi K, Mori M (2002b) G protein gamma 7 expression as a new clinicopathological marker in patients with intrahepatic cholangiocarcinoma. Arch Surg 137: $181-185$

van der Vlag J, Otte AP (1999) Transcriptional repression mediated by the human polycomb-group protein EED involves histone deacetylation. Nat Genet 23: $474-478$

van Kemenade FJ, Raaphorst FM, Blokzijl T, Fieret E, Hamer KM, Satijn DP, Otte AP, Meijer CJ (2001) Coexpression of BMI-1 and EZH2 polycomb-group proteins is associated with cycling cells and degree of malignancy in B-cell non-Hodgkin lymphoma. Blood 97: 3896-3901

Varambally S, Dhanasekaran SM, Zhou M, Barrette TR, Kumar-Sinha C, Sanda MG, Ghosh D, Pienta KJ, Sewalt RG, Otte AP, Rubin MA, Chinnaiyan AM (2002) The polycomb group protein EZH2 is involved in progression of prostate cancer. Nature 419: 624-629

Visser HP, Gunster MJ, Kluin-Nelemans HC, Manders EM, Raaphorst FM, Meijer CJ, Willemze R, Otte AP (2001) The polycomb group protein EZH2 is upregulated in proliferating, cultured human mantle cell lymphoma. Br J Haematol 112: $950-958$ 